CLINICAL STUDY

\title{
Resistin levels in hyperthyroid patients before and after restoration of thyroid function: relationship with body weight and body composition
}

Gerasimos E Krassas, Nikolaos Pontikides, Kostas Loustis, Georgios Koliakos ${ }^{1}$, Theodoros Constantinidis ${ }^{2}$ and Dimitrios Panidis ${ }^{3}$

Department of Endocrinology, Diabetes and Metabolism, Panagia General Hospital, N. Plastira 22, Thessaloniki, Greece 551 32, ${ }^{1}$ Department of Biological Chemistry, Aristotle University of Thessaloniki, Thessaloniki, Greece, ${ }^{2}$ Department of Epidemiology and Hygiene, Dimokritio University of Thrace, Thrace, Greece and ${ }^{3}$ Division of Endocrinology and Human Reproduction, Second Department of Obstetrics and Gynecology, Medical School, Aristotle University of Thessaloniki, Greece

(Correspondence should be addressed to G E Krassas; Email: krassas@the.forthnet.gr)

\begin{abstract}
Background: Resistin is a recently discovered peptide hormone that belongs to a family of tissue-specific resistin-like molecules. To date, very few studies have reported on resistin concentrations in hyperthyroid patients, and they present controversial results.

Objectives: To undertake a controlled, prospective study to investigate resistin concentrations in hyperthyroidism before and after restoration of euthyroidism and to correlate the results with body weight, body fat, waist circumference and body mass index (BMI).

Patients and Methods: A total of 43 hyperthyroid patients (12 men and 31 women) were investigated, in addition to 23 controls. Anthropometric parameters and resistin concentrations were measured. All the patients commenced taking antithyroid drugs and 3-4 months later the same investigations were performed in 36 of the 43 individuals.

Results: Hyperthyroid patients exhibited increased resistin concentrations in comparison with controls. Normalization of thyroid hormones was accompanied by a significant decrease in resistin concentration. A sex difference was also found, men showing a significant decrease in resistin concentrations, whereas in women no such difference was found. Resistin concentrations did not correlate with different anthropometric parameters, age and thyroid hormones, either before or after treatment.

Conclusions: This study demonstrates for the first time that, although resistin concentrations are increased in hyperthyroidism, they are not associated with body weight, body fat, waist circumference or BMI, which makes it unlikely that resistin plays a crucial part in thermogenesis and energy homeostasis in thyrotoxic patients.
\end{abstract}

European Journal of Endocrinology 153 217-221

\section{Introduction}

Resistin is a hormone that is expressed predominantly in adipocytes $(1,2)$, although resistin-like molecules are expressed by other tissues (3). It was originally named by Steppan et al. (4) for its resistance to insulin (resist $+\mathrm{in}[$ sulin]). It circulates in the blood and is a peptide hormone that belongs to a family of tissuespecific resistin-like molecules (5). Resistin mRNA encodes a 114 amino acid polypeptide containing a 20 amino acid signal sequence (4). Resistin is expressed in white adipose tissue, with the greatest concentrations in female gonadal adipose tissue (4). Insulin has been suggested as a major inhibitor of its production (6), which may explain the low levels of resistin mRNA in insulin resistance.

Although the first report proposed that serum concentrations of resistin would be increased in the obese state, a number of later publications have demonstrated decreased expression of the resistin gene in obesity (7). Moreover, genetic variations in the resistin gene did not show any association with obesity or (non-insulindependent) type 2 diabetes mellitus in Italian (8) or Japanese (9) populations. In one recent study in humans (10), it was demonstrated that resistin concentrations are not associated with markers of insulin resistance or obesity, and are not regulated by fasting or by the administration of leptin. It was concluded 
that circulating resistin is unlikely to have a major role in obesity, insulin resistance, or energy homeostasis in humans.

Until now, the role of resistin in human diseases and physiology has remained elusive. It may have a mechanism of action the opposite of that observed for adiponectin. Conceptually, it is interesting that adipose tissue secretes hormones that have both positive and negative effects on hepatic insulin sensitivity (11). To date, very few studies have reported on resistin concentrations in patients with hyperthyroidism before and after normalization of circulating thyroid hormones, and they present conflicting results. In one such study, resistin concentrations were significantly reduced in patients with hyperthyroidism in comparison with those in euthyroid individuals, but attainment of euthyroidism was not accompanied by a significant modification of resistin concentrations. The authors concluded that resistin might be implicated in the insulin-resistant state that accompanies thyrotoxicosis (12). In another report (13), thyrotoxic individuals were investigated who had received radioiodine treatment and became clinically and chemically hypothyroid. Resistin concentrations were measured when the patients were in the thyrotoxic state and after they had become hypothyroid, and were found to be significantly decreased in the latter state.

The aim of this controlled, prospective study was to investigate resistin concentrations in hyperthyroidism - a disease in which weight loss is one of the main manifestations - before and after restoration of euthyroidism, and to correlate the results with body weight, body fat, waist circumference and body mass index (BMI). Such data, to the best of our knowledge, have not been published previously.

\section{Material and methods}

A total of 43 hyperthyroid patients (12 men and 31 women) mean age $47.8 \pm 13.7$ years (range 19-75 years) participated in the study. All patients were newly diagnosed and recruited from the Endocrine Department of Panagia Hospital, Thessaloniki. The diagnosis was established by clinical examination and measurements of serum total triiodothyronine $\left(\mathrm{tT}_{3}\right)$, free thyroxine $\left(\mathrm{fT}_{4}\right)$ and thyrotropin (TSH). In all patients, measurements of height, body weight, body fat and waist circumference were carried out by the same physician (KL). BMI was calculated as the ratio of body weight to body height squared $\left(\mathrm{kg} / \mathrm{m}^{2}\right)$, and body fat was estimated using a legto-leg bioelectrical impedance method (14); body weight was measured to the nearest $500 \mathrm{~g}$, using a standard beam-balance scale. During the measurements, the patients were dressed in light underclothing. Body height was measured to the nearest $0.5 \mathrm{~cm}$. Patients with clinical symptoms of thyroid eye disease (other than mild forms), other comorbidity or who were receiving medication were excluded from the study. After an overnight fast, blood was taken at $0900 \mathrm{~h}$ for measurement of resistin.

Twenty-three euthyroid normal individuals (10 men and 13 women), mean age $47.8 \pm 11.4$ years (range 24-71 years), matched for age (5-year cohorts), BMI and body fat in the hyperthyroid state, served as controls. In all the control individuals, the same measurements were performed as in the patients.

All anthropometric data for patients and controls are presented in Table 1.

All 43 patients commenced taking antithyroid drugs, and 3-4 months after initiation of treatment, when euthyroidism was achieved, resistin concentrations, BMI, body weight, body fat and waist circumference were re-measured in 36 of the 43 (nine men, 27 women).

The serum concentrations of $\mathrm{tT}_{3}, \mathrm{fT}_{4}$, and $\mathrm{TSH}$ were measured by standard, commercial radioimmunoassay kits (Brahms, Henningsdorf, Germany). Normal values of these parameters are presented in Table 1.

The serum concentration of resistin was measured using a commercial enzyme immunoassay kit (Phoenix Pharmaceuticals Inc., Belmond, CA, USA). The assay was performed on 96-well polystyrene platers precoated with secondary antibody that can bind to the Fc fragment of the primary antibody; the Fab fragment of the primary antibody binds specifically with resistin. A competitive immunoassay approach was followed, with biotin-labelled resistin: the biotinylated peptide interacts with streptavidin-horseradish peroxidase, which catalyses the peroxidation of the substrate $3,3^{\prime}, 5,5^{\prime}$-tetramethylbenzidine, to produce a coloured derivative. The enzymatic reaction was stopped by HCl. A standard curve with known concentrations of resistin was prepared and resistin serum concentrations were determined according to this standard curve. An intra-assay variation of $8.4 \%$ was calculated for a sample with a concentration of about $30 \mathrm{ng} / \mathrm{ml}$ measured six times in the same assay. An interassay variation of $9.4 \%$ was calculated for the same sample measured at six different sessions.

The study was approved by the hospital Ethics Committee and all patients and controls gave informed consent to participate.

\section{Statistical analysis}

SSPSS 8.0 software (SPSS Inc., Chicago, IL, USA) was used for statistical analyses, and $P<0.05$ (two-tailed) was considered statistically significant for all analyses. Normality of distribution was tested by the Kolmogorov-Smirnov goodness of fit test. All parameters tested were normally distributed. Comparisons were performed by two-tailed unpaired and paired $t$-tests. Descriptive statistics are given as mean \pm S.D. for all variables. Pearson's and Kendall's correlation coefficients were used to evaluate the association between serum 
Table 1 Anthropometric and hormonal parameters (mean \pm S.D.) in hyperthyroid patients before and after restoration of euthyroidism, and in controls.

\begin{tabular}{|c|c|c|c|c|c|c|c|c|}
\hline & \multicolumn{4}{|c|}{ Patients } & \multicolumn{2}{|c|}{ Controls (C) } & \multicolumn{2}{|c|}{$P$ value } \\
\hline & \multicolumn{2}{|c|}{ Before treatment $(\mathrm{B})$} & \multicolumn{2}{|c|}{$\begin{array}{l}\text { After reaching } \\
\text { euthyroidism }(A)\end{array}$} & \multirow[b]{2}{*}{$n$} & \multirow[b]{2}{*}{ Value } & \multirow[b]{2}{*}{$B$ vs $C$} & \multirow[b]{2}{*}{$A$ vs $C$} \\
\hline & $n$ & Value & $n$ & Value & & & & \\
\hline Age (years) & 43 & $47.8 \pm 13.7$ & 36 & & 23 & $47.8 \pm 11.4$ & NS & \\
\hline Men & 12 & $48.4 \pm 16.4$ & 9 & & 10 & $48.2 \pm 12.4$ & & \\
\hline Women & 31 & $47.2 \pm 12.2$ & 27 & & 13 & $47.8 \pm 10.9$ & & \\
\hline $\begin{array}{l}\text { Total } \mathrm{T}_{3}(\mathrm{nmol} / \mathrm{l}) \\
\quad(\mathrm{NR}=1.08-3.08)\end{array}$ & 43 & $5.8 \pm 2.6$ & & $1.7 \pm 0.7$ & & $1.8 \pm 1.1$ & 0.002 & NS \\
\hline $\begin{array}{l}\text { Free }_{4}(\mathrm{pmol} / \mathrm{l}) \\
\quad(\mathrm{NR}=9.0-25.7)\end{array}$ & 43 & $44.7 \pm 12.9$ & & $19.3 \pm 7.7$ & & $18.7 \pm 6.9$ & 0.002 & NS \\
\hline $\begin{array}{l}\mathrm{TSH}(\mathrm{mlU} / \mathrm{l}) \\
\quad(\mathrm{NR}=0.25-4.5)\end{array}$ & 43 & $0.005 \pm 0.13$ & & $3.5 \pm 6.3$ & & $1.8 \pm 1.9$ & 0.000 & 0.03 \\
\hline Body weight (kg) & 43 & $66.1 \pm 12.8$ & & $68.1 \pm 13.1$ & & $67.9 \pm 14.1$ & NS & NS \\
\hline $\mathrm{BMI}\left(\mathrm{kg} / \mathrm{m}^{2}\right)$ & 43 & $24.4 \pm 4.5$ & & $25.3 \pm 4.6$ & & $25.3 \pm 3.9$ & NS & NS \\
\hline Waist circ. $(\mathrm{cm})$ & 43 & $83.8 \pm 12.6$ & & $85.6 \pm 12.1$ & & $87.2 \pm 9.4$ & NS & NS \\
\hline Body fat $(\%)$ & 43 & $24.9 \pm 10.4$ & & $29.2 \pm 10.1$ & & $28.5 \pm 9.2$ & NS & NS \\
\hline Resistin (ng/ml) & 43 & $11.0 \pm 6.5$ & & $6.8 \pm 4.3$ & & $6.1 \pm 3.7$ & 0.002 & NS \\
\hline
\end{tabular}

NR, Normal range; circ., circumference.

resistin concentrations and different anthropometric parameters (body weight, BMI, body fat and waist circumference), the changes (value after treatment minus value before) and the concentrations of thyroid hormones and TSH.

\section{Results}

All hyperthyroid patients had increased concentrations of $\mathrm{tT}_{3}$ and $\mathrm{fT}_{4}$ and suppressed concentrations of TSH, whereas after 3-4 months of treatment with antithyroid drugs all the patients had normal concentrations of thyroid hormones and TSH, with the exception of the latter, which in some patients remained suppressed (Table 1).

Patients with hyperthyroidism exhibited increased resistin concentrations in comparison with euthyroid control individuals (11.0 \pm 6.5 compared with $6.1 \pm 3.7 \mathrm{ng} / \mathrm{ml}, P=0.002$; Table 1, Fig. 1). Normalization of circulating thyroid hormones 3-4 months after the initiation of treatment was accompanied by a significant decrease in resistin concentrations (11.0 \pm 6.5 compared with $6.8 \pm 4.3 \mathrm{ng} / \mathrm{ml}, P=0.006$; Table 2); after treatment, resistin concentrations did not differ from those in euthyroid controls (6.8 \pm 4.3 compared with $6.1 \pm 3.7 \mathrm{ng} / \mathrm{ml}, P=$ NS; Table 1 , Fig. 1).

A sex difference also was found for resistin concentrations. A significant difference was found in male patients before and after treatment $(12.3 \pm 7.7 \mathrm{com}$ pared with $7.8 \pm 4.0 \mathrm{ng} / \mathrm{ml}, P=0.046)$, whereas no such difference was found in women $(10.2 \pm 5.9$ compared with $6.3 \pm 4.4 \mathrm{ng} / \mathrm{ml}, P=\mathrm{NS}$ ) (Table 2, Fig. 1). Moreover, no differences in resistin concentrations were demonstrated between men and women either before or after treatment.
As expected, significant changes were noted in different anthropometric parameters studied in patients before and after they had attained euthyroidism, and between men and women (Table 2). Finally, resistin concentrations did not correlate with thyroid hormones, different anthropometric parameters or age, either before or after treatment.

\section{Discussion}

The findings of this study show that resistin concentrations are increased in hyperthyroidism and reduced

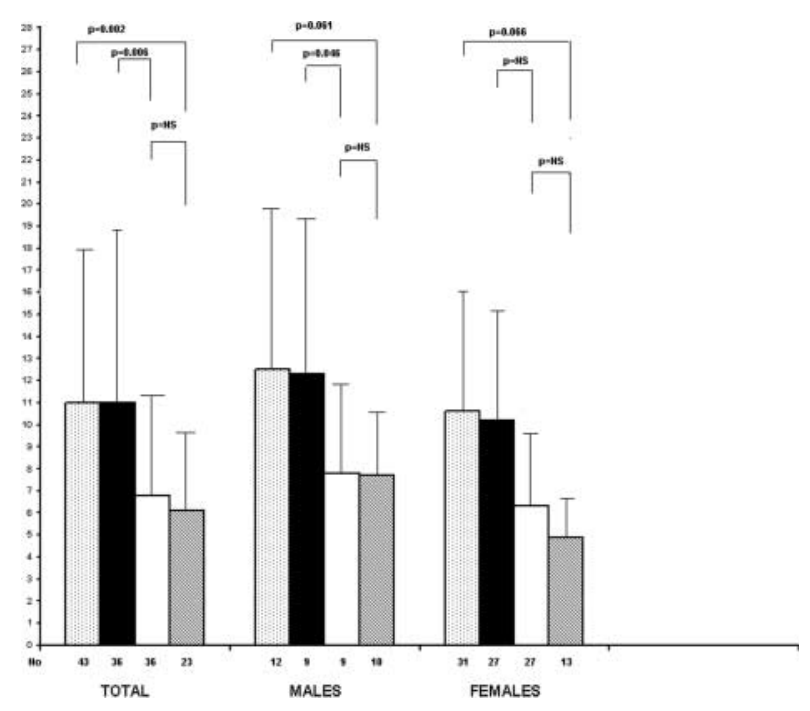

Figure 1 Resistin concentrations in hyperthyroid patients before and after attainment of euthyroidism, and in controls. number in total population; $\mathbf{\square}$, patients who were followed up; $\square$, patients in the euthyroid state; $\mathbb{\mathbb { Q }}$, controls. 
Table 2 Sex differences in anthropometric parameters and resistin concentrations (mean \pm S.D.) in hyperthyroid patients before and after restorion of thyroid function.

\begin{tabular}{|c|c|c|c|c|c|c|c|c|c|}
\hline & \multicolumn{3}{|c|}{ Before treatment (B) } & \multicolumn{3}{|c|}{ After reaching euthyroidism (A) } & \multicolumn{3}{|c|}{$P$ value (B vs $A$ ) } \\
\hline & Total & Men & Women & Total & Men & Women & Total & Men & Women \\
\hline$n$ & 36 & 9 & 27 & 36 & 9 & 27 & 36 & 9 & 27 \\
\hline $\begin{array}{l}\text { Body weight }(\mathrm{kg}) \\
\text { Change }\end{array}$ & $64.9 \pm 12.9$ & $74.6 \pm 12.8$ & $61.5 \pm 11.3$ & $\begin{array}{c}68.1 \pm 13.1 \\
3.1 \pm 2.6\end{array}$ & $78.8 \pm 13.8$ & $64.2 \pm 10.6$ & 0.000 & 0.002 & 0.000 \\
\hline $\begin{array}{c}\text { BMI }\left(\mathrm{kg} / \mathrm{m}^{2}\right) \\
\text { Change }\end{array}$ & $24.1 \pm 4.7$ & $24.2 \pm 5.2$ & $24.1 \pm 4.6$ & $\begin{array}{r}25.3 \pm 4.6 \\
1.1 \pm 1.0\end{array}$ & $25.6 \pm 5.7$ & $25.2 \pm 4.3$ & 0.000 & 0.007 & 0.000 \\
\hline $\begin{array}{l}\text { Waist circ. }(\mathrm{cm}) \\
\text { Change }\end{array}$ & $82.8 \pm 12.7$ & $91.1 \pm 13.5$ & $80.1 \pm 11.3$ & $\begin{array}{c}85.6 \pm 12.1 \\
2.9 \pm 3.0\end{array}$ & $93.8 \pm 14.0$ & $83.0 \pm 10.4$ & 0.000 & 0.021 & 0.000 \\
\hline $\begin{array}{l}\text { Body fat (\%) } \\
\text { Change }\end{array}$ & $24.8 \pm 11.0$ & $18.5 \pm 11.4$ & $27.0 \pm 10.1$ & $\begin{array}{c}29.2 \pm 10.1 \\
4.4 \pm 3.5\end{array}$ & $32.2 \pm 11.7$ & $31.8 \pm 8.3$ & 0.000 & 0.002 & 0.000 \\
\hline Resistin (ng/ml) & $11.0 \pm 6.5$ & $12.3 \pm 7.7$ & $10.2 \pm 5.9$ & $6.8 \pm 4.3$ & $7.8 \pm 4.0$ & $6.3 \pm 4.4$ & 0.006 & 0.046 & NS \\
\hline
\end{tabular}

circ., circumference.

after a euthyroid state has been reached. A sex difference also was found for resistin concentrations, which in men exhibited a significant decrease after normalization of thyroid function. Moreover, it was found that resistin concentrations did not correlate with body weight, body fat, waist circumference or BMI, either before or after euthyroidism was restored. Finally, as expected, significant changes were noted in different anthropometric parameters in patients before and after the attainment of euthyroidism.

To date, there have been only a few studies that have reported on this issue. Iglesias et al. (12) investigated 20 hyperthyroid patients and provided information regarding body weight and BMI before and after treatment of the hyperthyroidism. They demonstrated that patients exhibited significantly reduced resistin concentrations in comparison with euthyroid individuals $(6.4 \pm 0.8$ compared with $8.4 \pm 0.7 \mu \mathrm{g} / \mathrm{l}, P<0.05)$. Normalization of circulating thyroid hormone concentrations was not followed by any significant change in resistin concentrations $(5.4 \pm 0.7 \mu \mathrm{g} / \mathrm{l}, P=\mathrm{NS})$. After adjustment for BMI, resistin concentrations were similar in hyperthyroid patients and euthyroid individuals. However, normalization of thyroid function produced a significant reduction in resistin concentrations (from $0.28 \pm 0.03$ to $0.21 \pm 0.03 \mu \mathrm{g} / \mathrm{l}$ per unit of BMI; $P<0.05)$. The main drawbacks of that study were the small number of patients investigated and the lack of measurement of body composition. In another recent study, Yaturu et al. (13) investigated 69 patients with Graves' disease, 32 of whom were followed after radioiodine treatment when they were hypothyroid, representing a hypothyroid group. The authors found a significant difference in resistin concentrations between that group and those with Graves' disease $(6.37 \pm 0.09$ compared with $5.81 \pm 0.13 \mathrm{ng} / \mathrm{ml}, \quad P=0.0001)$. It should be noted that this was an uncontrolled study, in which measurements of body composition and BMI were not made; moreover, resistin concentrations were compared with those in thyrotoxic patients who became hypothyroid after radioiodine treatment.
A further disadvantage of the study is that it is not clear whether paired or unpaired $t$-tests were used.

The present study is the first to report the effect of hyperthyroidism - a disease in which weight loss is a predominant feature - on resistin concentrations in correlation with BMI and body composition. Although BMI, body weight, waist circumference and body fat were increased after treatment, as expected, no association was found with resistin concentrations, either before or after restoration of thyroid function.

Little is known about the effects of weight loss on resistin regulation. In a recent study (15), it was demonstrated that modest energy restriction and weight loss are not associated with alteration in circulating resistin concentrations in healthy, normalweight volunteers. These findings are similar to results in obese individuals with insulin resistance who were enrolled in a behaviour-modification programme to induce weight loss (16), and similar to results from healthy lean individuals exposed to caloric deprivation for 2 days (10). In the latter study, it was found that resistin did not correlate with BMI, waist-to-hip ratio, fat mass or insulin resistance.

To the best of our knowledge, no study to date has reported on the effect of weight gain on resistin regulation. Our results suggest that, although resistin concentrations are increased in thyrotoxic patients, this is unlikely to play a major part in energy homeostasis in this group.

Another interesting finding of this study was that thyrotoxic men had a significant difference in resistin concentrations before and after attaining euthyroidism, whereas this was not found in female patients; a sex difference in favour of men was also found by Iglesias et al. (12). These findings are in disagreement with other recent data showing that resistin concentrations exhibit a sexual dimorphism, with women having greater concentrations than men ( $\sim 20 \%$ greater) (10). A change in the metabolic clearance of resistin in hyperthyroidism cannot be excluded, and may explain this sex difference; data on this subject are absent from 
the literature. Furthermore, a number of hormones and factors such as adiponectin, leptin, tumour necrosis factor- $\alpha$ and others have been discovered recently, which are expressed by adipose tissue and appear to have key roles in thermogenesis and energy metabolism. However, the effect that these peptides may have on circulating concentrations of resistin has not yet been fully identified and may explain, at least in part, the sexual dimorphism with regard to resistin concentrations that is seen in hyperthyroid patients, in favour of men.

In conclusion, this study demonstrates that, although resistin concentrations are increased in hyperthyroidism, they are not associated with BMI, body fat, waist circumference and body weight, which makes it unlikely that resistin plays a crucial part in energy homeostasis in thyrotoxic patients. More studies are needed, with special emphasis on the concentrations of other adipokines and factors, before final conclusions can be drawn regarding the physiological implications and the aetiology of this very interesting finding.

\section{References}

1 Steppan CM, Bailey ST, Bhat S, Brown EJ, Banerjee RR, Wright CM, Patel HR, Ahima RS \& Lazar MA. The hormone resistin links obesity to diabetes. Nature $2001409307-312$.

2 Rajala MW, Lin Y, Ranalletta M, Yang XM, Qian H, Gingerich R, Barzilai N \& Scherer PE. Cell type-specific expression and coregulation of murine resistin and resistin-like molecule-alpha in adipose tissue. Molecular Endocrinology 200216 1920-1930.

3 Rajala MW, Obici S, Scherer PE \& Rossetti L. Adipose-derived resistin and gut-derived resistin-like molecule-beta selectively impair insulin action on glucose production. Journal of Clinical Investigation $2003111225-230$

4 Steppan CM \& Lazar MA. Resistin and obesity-associated insulin resistance. Trends in Endocrinology and Metabolism 200213 $18-23$.

5 Steppan CM, Brown EJ, Wright CM, Bhat S, Banerjee RR, Dai CY, Enders GH, Silberg DG, Wen X, Wu GD \& Lazar MA. A family of tissue-specific resistin-like molecules. PNAS 200198 502-506.

6 Haugen F, Jorgensen A, Drevon CA \& Trayhurn P. Inhibition by insulin of resistin gene expression in 3T3-L1 adipocytes. FEBS Letters 2001507 105-108.
7 Ukkola O. Resistin - a mediator of obesity-associated insulin resistance or an innocent bystander? European Journal of Endocrinology $2002147571-574$.

8 Sentinelli F, Romeo S, Arca M, Filippi E, Leonetti F, Banchieri M, Di Mario U \& Baroni MG. Human resistin gene, obesity, and type 2 diabetes: mutation analysis and population study. Diabetes $200251860-862$.

9 Osawa H, Onuma H, Murakami A, Ochi M, Nishimiya T, Kato K, Shimizu I, Fujii Y, Ohashi J \& Makino H. Systematic search for single nucleotide polymorphisms in the resistin gene: the absence of evidence for the association of three identified single nucleotide polymorphisms with Japanese type 2 diabetes. Diabetes $2002 \mathbf{5 1}$ $863-866$.

10 Lee JH, Chan JL, Yiannakouris N, Kontogianni M, Estrada E, Seip R, Orlova C \& Mantzoros CS. Circulating resistin levels are not associated with obesity or insulin resistance in humans and are not regulated by fasting or leptin administration: cross-sectional and interventional studies in normal, insulin-resistant, and diabetic subjects. Journal of Clinical Endocrinology and Metabolism $2003 \mathbf{8 8} 4848-4856$.

11 Rajala MW \& Scherer PE. Adipose tissue-derived hormones: their role in energy homeostasis and pathophysiology. Topical Endocrinology 200424 6-9.

12 Iglesias P, Alvarez Fidalgo P, Codoceo R \& Diez JJ. Serum concentrations of adipocytokines in patients with hyperthyroidism and hypothyroidism before and after control of thyroid function. Clinical Endocrinology $200359621-629$.

13 Yaturu S, Prado S \& Grimes SR. Changes in adipocyte hormones leptin, resistin, and adiponectin in thyroid dysfunction. Journal of Cellular Biochemistry 200493 491-496.

14 Utter AC, Nieman DC, Ward AN \& Butterworth DE. Use of the leg-to-leg bioelectrical impedance method in assessing body-composition change in obese women. American Journal of Clinical Nutrition $199969603-607$.

15 Wolfe BE, Jimerson DC, Orlova C \& Mantzoros CS. Effect of dieting on plasma leptin, soluble leptin receptor, adiponectin and resistin levels in healthy volunteers. Clinical Endocrinology $2004 \mathbf{6 1}$ $332-338$.

16 Monzillo LU, Hamdy O, Horton ES, Ledbury S, Mullooly C, Jarema C, Porter S, Ovalle K, Moussa A \& Mantzoros CS. Effect of lifestyle modification on adipokine levels in obese subjects with insulin resistance. Obesity Research 200311 1048-1054.

Received 18 March 2005

Accepted 13 May 2005 